\title{
The Effectiveness of Group Cognitive Behavioral Therapy in Treating Obsessive-Compulsive Disorder in Women with Multiple Sclerosis (MS): A randomized double-blind controlled trial
}

\author{
Mehdi Sayyah $^{1}$, Parisa Bagheri ${ }^{2}$, Negar Karimi ${ }^{3}$, Azizreza Ghasemzadeh ${ }^{4}$
}

${ }^{1}$ Psychiatrist, Associate Professor, Faculty member of Jundishapur University, Ahvaz, Iran

${ }^{2}$ Master in Clinical Psychology, Education and Psychology Faculty, Islamic Azad University, Khomein Branch, Iran

${ }^{3}$ Master in Cognitive Psychology, Institute of Cognitive Science Studies, Tehran, Iran

${ }^{4}$ Lecturer in Rehabilitation Science, University of Applied Sciences, Tehran Welfare Organization, Tehran, Iran

\section{Type of article: Original}

\begin{abstract}
Background: Obsessive-compulsive disorder (OCD) is one of the most prevalent psychiatric disorders and can cause problems for individuals in all aspects of life, including social and personal dimensions.

Objective: To study the effect of group cognitive-behavioral therapy on the reduction of OCD symptoms in female participants with multiple sclerosis (MS).

Methods: This double-blind randomized control trial was conducted from May 2012 to December 2014. The participants included 75 patients with MS who suffered from OCD and were referred to the Loghman Hakim and Imam Khomeini hospitals in Tehran, Iran. Thirty participants had been diagnosed through Yale-Brown Obsessive-Compulsive Symptoms (Y-BOCS). The participants were randomly divided into an experimental group $(n=15)$ and a control group $(n=15)$. Eleven sessions of cognitive-behavioral therapy were provided for the experimental group. Patients in the control group continued with their normal living. Hypotheses were tested using an analysis of covariance (ANCOVA).

Results: A significant reduction was found in the experimental group's obsessive-compulsive symptoms after cognitive-behavioral therapy $(\mathrm{p}<0.001)$. In addition, mean scores for participants in the experimental group were significantly lower than for those in the control group $(\mathrm{p}=0.000)$.

Conclusion: It can be inferred that cognitive-behavioral therapy could considerably reduce OCD symptoms in women with MS. The application of this method by therapists, especially Iranian clinicians, is recommended.

Trial registration: The trial is registered at the Thai Clinical Trial Registry (clinicaltrials.in.th) with the TCR identification number TCTR20150927001.

Funding: The authors received no financial support for the research, authorship, and/or publication of this article.

Keywords: Multiple Sclerosis, Obsessive-Compulsive Disorder, Cognitive-Behavioral Therapy, Women
\end{abstract}

\section{Introduction}

Obsessive-compulsive disorder (OCD) is a potentially devastating disease that could pose problems in terms of a person's job, education, and social or personal relationships as well as lead to social and economic inability for patients and their family members (1). The studies showed that the prevalence of OCD among adults in the United States is about $1.2 \%$ in one year while the overall estimation is about $2.3 \%$ for a life span. OCD prevalence in adult females is slightly higher than that in adult males, whereas the rate is higher for male children than female children (2). OCD is considered one of the most epidemic psychiatric disorders in Iran. It is a severe and debilitating anxiety disorder that affects one out of 40 adults $(0.7 \%$ in males and $2.8 \%$ in females) in Iran $(0.9$ to $4.4 \%$ of the total population). The prevalence of the disorder in the Iranian adult population is estimated to be about $1.8 \%$. OCD is the fourth most common psychiatric illness in the world, following schizophrenia and bipolar disorder (3). The disorder usually begins in childhood or early adulthood, and its chronic process can often have severe and negative impacts

\section{Corresponding author:}

Azizreza Ghasemzadeh, Lecturer in Rehabilitation Science, University of Applied Sciences, Tehran Welfare Organization, Tehran, Iran. Tel: +98.9331332853, Email: a.ghasemzadeh@irimc.org

Received: July 25, 2015, Accepted: November 26, 2015, Published: April 2016 iThenticate screening: November 12, 2015, English editing: January 13, 2016, Quality control: March 22, 2016 (C) 2016 The Authors. This is an open access article under the terms of the Creative Commons Attribution-NonCommercialNoDerivs License, which permits use and distribution in any medium, provided the original work is properly cited, the use is non-commercial and no modifications or adaptations are made. 
on patients' psychosocial and occupational functioning (4). Researchers have reported the existence of OCD in patients with multiple sclerosis (MS) (5-7) at a rate of $8.6 \%$. The etiology of OCD in MS is unknown, but some researchers believe that OCD is the result of the disruption of the functional connection between cortico-cortical and/or cortico-subcortical brain regions (ibid.). In addition, autoimmunity may play a role in the pathogenesis of OCD in MS. Researchers have shown a link between OCD and autoimmunity (8). The main symptoms of OCD are frequent and disabling obsessional thoughts and actions. Intellectual obsessions are annoying, repetitive, and persistent thoughts, images, or impulses created unintentionally and involuntarily and that arouse significant anxiety or confusion. OCD is often particular content for the person and associated with the data and events completely disproportionate to the patient. Obsessions often lead to patients' mental resistance, but they are difficult to control. The patients usually recognize that the obsessions are created by their minds, and most of them are meaningless or irrational; however, the level of a person's insight into the meaninglessness of obsessions differ significantly $(3,8)$. People often have obsessive thoughts and beliefs that form during their childhood and have prompted personality disorders. In addition, dysfunctional methods of facing these negative thoughts and behaviors cause a negative temperament and neutral behavior. Before taking medicine and engaging in cognitive-behavioral therapy, people with OCD were thought to be generally incurable. Fortunately, today, new treatments can help most of these patients. Although in some cases OCD is completely incurable, in most cases long-term symptoms could be reduced through the comprehensive treatment of the combined use of medication and psychotherapy. In the past two decades, treatments have focused on changing the beliefs and cognitive assessment of OCD patients. OCD theories consider irrational beliefs as the main cause of the disorder. Many studies have shown that our beliefs and evaluations have a direct relationship with OCD (9). A case has also been made for an approach to OCD patients who were resistant to conventional cognitive-behavioral therapy (9), in which cognitive therapy (CT) was designed to resolve dysfunctional beliefs; results indicated that treatment was encouraging. CT treatment focuses on improving and understanding beliefs related to OCD (like certainty, perfectionism, and inflated responsibility). It seems that CT is acceptable for many OCD patients and improves their symptoms (10). Six patients with obsessive thoughts but without obsessive behavior were chosen and underwent cognitive therapy (11). This study was based on a single experimental case design conducted through a standard self-report questionnaire and assessed by clinicians; treatments focused exclusively on patients' beliefs. The results demonstrated that a significant number of patients had considerably improved, which was further demonstrated during the follow-up. The results of the relationship between OCD symptoms and beliefs associated with the obsessive disorder among students and a clinical sample showed that beliefs had strong mutual relationships with each other and were not sufficiently separated for more individual analysis (12). The total obsessive score was significantly correlated to all of the OCD symptoms after controlling for anxiety and depression variables. Researchers have also proposed a relationship between OCD symptoms and dysfunctional beliefs (13), and the results of their study revealed that the tendency to assess the danger and threat could significantly predict OCD symptoms in areas like washing, checking, doubting, obsession, and mental neutralization. Furthermore, it was represented that obsessive thoughts (obsessions) would be meaningfully predicted by controlling thoughts.

Based on the results of the aforementioned studies, the current study aimed to assess the effect of group cognitivebehavioral therapy in reducing the symptoms of obsessive-compulsive disorder in volunteer women with OCD and MS for therapy in Tehran. The research investigated whether or not cognitive-behavioral therapy would be effective in improving obsession beliefs and relieving OCD symptoms in women with MS.

\section{Material and Methods}

\subsection{Trial design}

Using a quasi-experimental method and medical records confirmed by physicians, 30 women whose Yale-Brown scores ranged between 20 and 25 were diagnosed as simultaneously suffering from OCD and MS. Patients were randomly divided into an experimental group $(n=15)$ and a control group $(n=15)$. The experimental group received group cognitive-behavioral therapy as the sample for 11 sessions. As Table 1 shows, participants were informed about the method, introduction, and treatment of exposure, etc., in the first sessions. Features of OCD personality and the relationship between anxiety, depression, and obsessive disorders were also explained to them. In the next session, dysfunctional assumption and modification techniques beliefs as well as beliefs in opposite methods were described. Finally, the last session was devoted to the post-test and efficacy method along with suggestions for further studies. Patients in the control group received no special therapy during treatment. All participants in both groups were taking selective serotonin re-uptake inhibitors or serotonin-specific reuptake inhibitors (SSRIs) identically and homogenized by relevant doctors. 
Table 1. Framework and Details of Therapy Sessions

\begin{tabular}{|c|c|}
\hline Therapy sessions & Session Activities \\
\hline Session 1 & $\begin{array}{l}\text { - Describing the procedure to participants } \\
\text { - Rules of the group and expectations of group members } \\
\text { - Relaxation training } \\
\text { - Writing thoughts } \\
\text { - Definition of obsession } \\
\text { - Definition of core beliefs }\end{array}$ \\
\hline Session 2 & $\begin{array}{l}\text { - Types to avoid and avoiding negative consequences } \\
\text { - Types of force } \\
\text { - Confident and counteractive methods and the most common ways of using them } \\
\text { - Antipathy } \\
\text { - Multiplicative factors of false obsessive behavior } \\
\text { - Treatment of exposure }\end{array}$ \\
\hline Session 3 & $\begin{array}{l}\text { - Distinction between thinking and feeling } \\
\text { - Training three columns A-B-C } \\
\text { - Features of obsessive-compulsive personality disorder and treatment of perfectionism }\end{array}$ \\
\hline Session 4 & $\begin{array}{l}\text { - Automatic thoughts and their characteristics } \\
\text { - Relationship among anxiety, depression, and obsession }\end{array}$ \\
\hline Session 5 & - Downward arrows defined and cognitive distortions \\
\hline Session 6 & - Definition of dysfunctional assumptions \\
\hline Session 7 & - Categories' beliefs and core beliefs and negative thoughts suggesting a common belief \\
\hline Session 8 & • Enjoying mental indulging \\
\hline Session 9 & - Modification technique beliefs \\
\hline Session 10 & - Belief in opposite method \\
\hline Session 11 & $\begin{array}{l}\text { - Posttest } \\
\text { - Review of administrative constraints } \\
\text { - Efficacy of methods } \\
\text { - Suggestions for future periods }\end{array}$ \\
\hline
\end{tabular}

\subsection{Population and sampling method}

The population of the research included 75 women with MS who had been referred to the two public hospitals in a center in Tehran during a given time. Their ages ranged from 20 to 45 years old; they held at least a diploma, were aware of their disease, and were inclined to join treatment groups.

\subsection{Instruments}

The self-assessment Yale-Brown obsessive-compulsive scale (Y-BOCS) is a tool used to identify the typology of $\mathrm{OCD}$ and assess the severity of symptoms. The Iranian version of the self-assessment form of Y-BOCS was employed in this study. A checklist of symptoms was applied to identify 36 types of obsessions and 23 types of compulsions derived from the clinical experience of Y-BOCS authors and other questionnaires (14). The reliability of Y-BOCS scale ranged between 0.72 and 0.98 based on test-retest, and its internal consistency coefficient was 0.89 . The validity of the survey was confirmed by clinicians (15). Those who scored 16 or higher on this scale were considered to be suffering from the disorder. Patients' scores before treatment usually ranged from 22 to 26 ; when scores dropped below 15, treatment is considered successful (5). In this study, participants' pre-treatment scores were generally above 25 .

\subsection{Outcomes}

To evaluate the effectiveness of group cognitive-behavioral therapy in reducing OCD symptoms in women with OCD and MS, the Y-BOCS was used, providing the researcher with a specific tool for measuring the intensity of OCD symptoms. The scale aims to solve the problems of existing rating scales for symptoms not under the effect of obsessions or compulsions. Y-BOCS includes 10 items, each of which range from zero (no symptoms) to four (extreme symptoms). In addition, regarding the severity of obsessions and compulsions, the scale has some separate subtotals (16). The patients completed the questionnaire, and the gathered data were analyzed using ANOVA. 


\subsection{Data collection and analysis}

In the present study, descriptive and inferential statistics (analysis of covariance) were used to compare pre-test and post-test means. The data were analyzed using SPSS software.

\subsection{Research ethics}

During the present research, all patients were protected against any harm and injury; their consent was also a key factor for conducting the research.

\section{Results}

Participants in the present research included 30 females, among whom 9 had a diploma, 16 had a bachelor's degree, and 5 had a master's degree. They ranged between 20 to 45 years old, with a mean of 30.25 years old. In addition, 12 applicants were married whereas the remaining 18 were single. As Table 2 shows, the F-value for cognitivebehavioral therapy (47.63) is greater than the critical value of $\mathrm{F}(4.21)$ for the $5 \%$ of error ( $\mathrm{DF}=1$ and 27$)$, so the null hypothesis stating that there would be no difference between scores of the control and experimental groups is rejected at the $95 \%$ confidence interval. In other words, cognitive-behavioral therapy is effective in determining OCD symptoms. In addition, lower mean scores for applicants in the experimental group (15.80) than the control group (18.84) indicated that cognitive-behavioral therapy could considerably reduce OCD symptoms. As Table 3 shows, the decrease in the mean scores between the pre- and posttest on the Obsessive Beliefs Questionnaire (OBQ) shows that cognitive-behavioral therapy was effective in reducing OCD symptoms in the experimental group. Considering Figures 1 and 2, it can be inferred that cognitive-behavioral therapy was effective in reducing OCD symptoms in the experimental group whereas the pre- and posttest scores in the control group were not different.

Table 2. Results of ANCOVA in the effectiveness of CBT on symptoms of obsessive-compulsive disorders

\begin{tabular}{|l|l|l|l|l|l|}
\hline $\begin{array}{l}\text { Source of } \\
\text { variations }\end{array}$ & Sum of squares & Degree of freedom & Mean of square & F & Significance \\
\hline Pretest & 280.56 & 1 & 280.56 & 160.21 & 0.00 \\
\hline CBT & 83.41 & 1 & 83.41 & 47.63 & 0.00 \\
\hline Error & 47.28 & 27 & 1.75 & & \\
\hline
\end{tabular}

Table 3. Measures of central tendency and distribution of symptoms of obsessive-compulsive disorders in control and experimental groups

\begin{tabular}{|l|l|l|l|l|l|l|l|}
\hline Group & Type of test & Mean & Median & Mode & SD & Minimum & Maximum \\
\hline \multirow{2}{*}{ Control } & Pretest & 19.92 & 19.21 & 16.01 & 2.98 & 16.01 & 26.33 \\
\cline { 2 - 8 } & Posttest & 18.84 & 20.09 & 20.09 & 2.71 & 14.18 & 23.63 \\
\hline \multirow{2}{*}{ Experimental } & Pretest & 20.33 & 19.53 & 9.50 & 5.49 & 9.50 & 30.46 \\
\cline { 2 - 8 } & Posttest & 15.80 & 15.47 & 13.95 & 4.00 & 6.85 & 23.63 \\
\hline
\end{tabular}

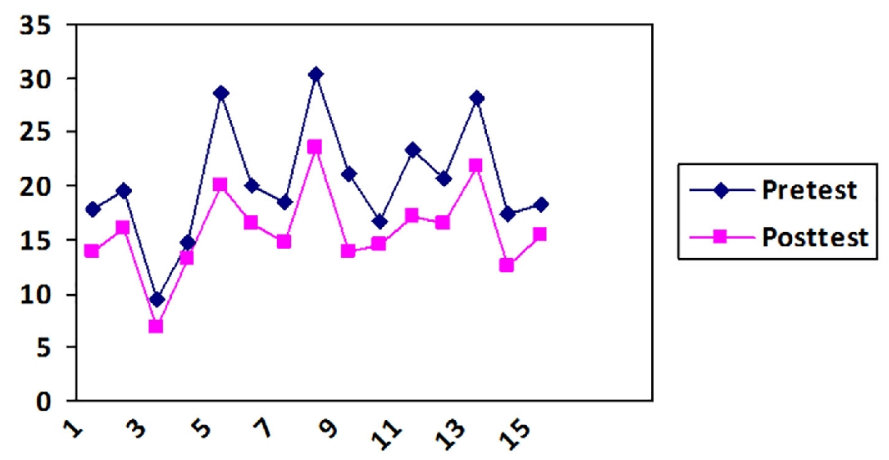

Figure 1. Pre- and posttest scores for experimental group with regard to obsessive-compulsive disorder 


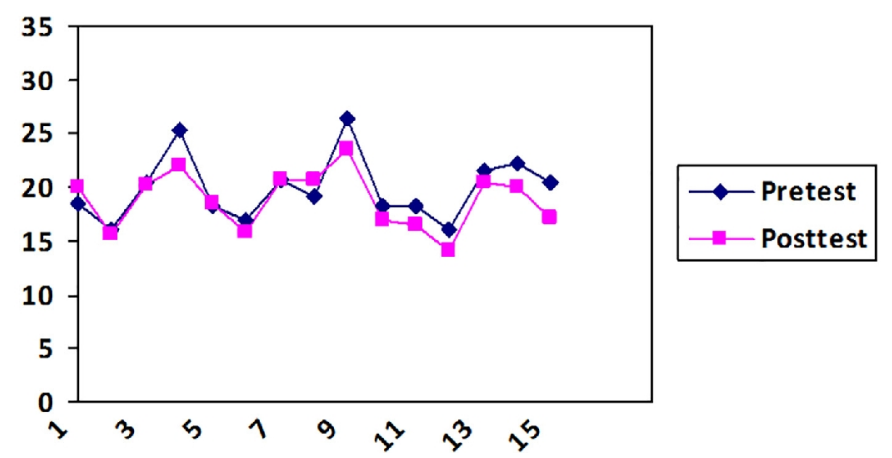

Figure 2. Pre- and posttest scores for experimental group with regard to obsessive-compulsive disorder

\section{Discussion}

With respect to the obtained results, group cognitive-behavioral therapy reduced OCD symptoms ( $\alpha=0.001)$. However, the combination of medication therapies and cognitive-behavioral therapy was not shown to be effective except in the PC only in the cognitive-behavioral therapy group. As people with MS experience a range of impairments and disabilities and those with progressive disease courses experience greater levels of impairment and disability than normal groups, it can be said that these findings are in line with results of other study, which indicated that cognitive rehabilitation might benefit some MS patients (17). Furthermore, as cognition has increasingly been recognized as a major feature of MS, its assessment and rehabilitation would become a greater priority (17). Researchers who investigated the efficacy of group cognitive-behavioral therapy to relieve OCD symptoms demonstrated that group cognitive-behavioral therapy was an effective treatment for OCD (18). Moreover, researchers who designed CT to relieve the dysfunctional beliefs showed that the modification of beliefs could be promising for the treatment of $\operatorname{OCD}(10,19)$. Other researchers have attempted to examine the relationship between obsessions and OCD symptoms, proposing that a relationship exists between OCD symptoms and dysfunctional beliefs $(11-13,20)$. Concurring with previous results, the findings revealed that assessing the danger and threat could significantly predict OCD symptoms in areas like washing, checking, doubting, obsession, and mental neutralization. Furthermore, obsessive thoughts (obsessions) could be meaningfully predicted through the control of thoughts. According to findings of this study along with results from other research, it can be concluded that group cognitive-behavioral therapy could improve OCD symptoms and is also influential in modifying obsessions; the subscales of the present study are consistent with such results $(12,13,21-22)$.

\section{Conclusions}

This research studied the effect of group cognitive-behavioral therapy on reducing OCD symptoms in a group of female participants with MS. Therefore, five patients with MS and OCD received treatment for 11 sessions. The findings emphasized that group cognitive-behavioral therapy can be an effective method in reducing OCD symptoms in women with MS, suggesting the relationship between OCD and different biological markers of MS, OCD response to anti-obsessive treatment in patients with MS, and the effect of OCD treatment on the course of MS.

\section{Registration code:}

The trial is registered at the Thai Clinical Trial Registry (clinicaltrials.in.th) with the TCR identification number TCTR20150927001.

\section{Funding:}

The authors received no financial support for the research, authorship, and/or publication of this article.

\section{Acknowledgments:}

The authors would like to thank the persons who participated in this study. They would also like to thank the hospital staff who helped the researchers during the procedures. This research received no specific grant from funding agencies in the public, commercial, or not-for-profit sectors.

\section{Conflict of Interest:}

There is no conflict of interest to be declared. 


\section{Authors' contributions:}

All authors contributed to this project and article equally. All authors read and approved the final manuscript.

\section{References:}

1) Jenike MA. Clinical practice. Obsessive-compulsive disorder. N Engl J Med. 2004; 350: 256-259. doi: 10.1056/NEJMcp031002, PMID: 14724305.

2) Ruscio A, Stein D, Chiu W, Kessler R. The epidemiology of obsessive-compulsive disorder in the National Comorbidity Survey Replication. Mol Psychiatry. 2008; 15(1): 53-63. doi: 10.1038/mp.2008.94, PMID: 18725912.

3) Mohammadi MR, Davidian H, Noorbala AA, Malekafzali H, Naghavi HR, Pouretemad HR, et al. An epidemiological study of psychiatric disorders in Iran. Hakim Research Journal. 2003; 6: 55-64.

4) Clark DA. Cognitive behavior therapy for obsessions and compulsions: New applications and Emerging trends. J Contemp Psychother. 2000; 30: 129-47. doi: 10.1023/A:1026562628287.

5) Steketee G. Treatment of obsessive-compulsive disorder. New York: Guilford Press; 1993. PMCid: PMC3323077.

6) George M, Kellner C, Fossey M. Obsessive-Compulsive Symptoms in a Patient with Multiple Sclerosis. J Nerv Ment Dis. 1989; 177(5): 304. doi: 10.1097/00005053-198905000-00010, PMID: 2708974.

7) Douzenis A, Michalopoulou PG, Voumvourakis C, Typaldou M, Michopoulos I, Lykouras L. Obsessivecompulsive disorder associated with parietal white matter multiple sclerosis plaques. World J Biol Psychiatry. 2009; 10: 956-60. doi: 10.1080/15622970701762528, PMID: 19995223.

8) Hoekstra P, Minderaa R. Tic disorders and obsessive-compulsive disorder: Is autoimmunity involved? Int Rev Psychiatry. 2005; 17(6): 497-502. doi: 10.1080/02646830500382003, PMID: 16401548.

9) Clark, David A. Cognitive-Behavioral Therapy for OCD. New York: Guilford Press, 2004. Print.

10) Sookman, Debbie, Gail Steketee. Directions in Specialized Cognitive Behavior Therapy For Resistant Obsessive-Compulsive Disorder: Theory And Practice Of Two Approaches. Cogn Behav Pract. 2007: 14(1): 1-17. doi: 10.1016/j.cbpra.2006.09.002.

11) Freeston MH, Léger E, Ladouceur R. Cognitive Therapy Of Obsessive Thoughts. Cogn Behav Pract. 2001; 8(1): 61-78. doi: 10.1016/S1077-7229(01)80045-6.

12) Faull M, Joseph S, Meaden A, Lawrence T. Obsessive Beliefs And Their Relation To ObsessiveCompulsive Symptoms. Clin Psychol Psychother . 2004;11(3): 158-67. doi: 10.1002/cpp.403.

13) Tolin DF, Woods CM, Abramowitz JS. Relationship between obsessive beliefs and obsessive- Compulsive symptoms. Cognitive Ther Res . 2003; 27 (6): 657-669. doi: 10.1023/A:1026351711837

14) . Goodman WK, Rasmussen SA, Price LH, Mazure L, Heninger GR, Charney D. Yale-Brown Obsessivecompulsive Scale (Y-BOCS). Verhaltenstherapie. 1991; 1(3): 226-33. doi: 10.1159/000257973.

15) Dadfar M, Bolhari J, Malakouti K, Bayan Zadeh A. An examination of the phenomenology of obsessivecompulsive disorder. The Quarterly Journal of thought and behavior (Andeeshe va Raftar). 2001; 7: 27-32.

16) Goodman WK1, Price LH, Rasmussen SA, Mazure C, Fleischmann RL, Hill CL, et al. The Yale-Brown Obsessive Compulsive Scale. I. Development, use, and reliability. Arch Gen Psychiatry. 1989 Nov;46(11):1006-11.PMid: 2684084.

17) Messinis L, Kosmidis MH, Lyros E, Papathanasopoulos P. Assessment and rehabilitation of cognitive impairment in multiple sclerosis. Int Rev Psychiatry. 2010; 22(1): 22-34. doi: 10.3109/09540261003589372, PMID: 20233112.

18) Jónsson H, Hougaard E. Group Cognitive Behavioural Therapy For Obsessive-Compulsive Disorder: A Systematic Review And Meta-Analysis. Acta Psychiatr Scand. 2009; 119(2): 98-106, doi: 10.1111/j.16000447.2008.01270.x, PMID: 18822090.

19) Chosak A, Marques L, Fama J, Renaud S, Wilhelm S . Cognitive Therapy For Obsessive-Compulsive Disorder: A Case Example. Cogn Behav Pract. 2009; 16(1): 7-17. doi: 10.1016/j.cbpra.2008.01.005.

20) Tolin DF, Brady RE, Hannan S. Obsessional Beliefs And Symptoms Of Obsessive-Compulsive Disorder In A Clinical Sample. J Psychopathol Behav . 2007; 30(1): 31-42. doi: 10.1007/s10862-007-9076-7.

21) Moulding R, Anglim J, Nedeljkovic M, Doron G, Kyrios M, Ayalon A. The Obsessive Beliefs Questionnaire (OBQ): Examination In Nonclinical Samples And Development Of A Short Version. Assessment. 2011; 18(3): 357-74. doi: 10.1177/1073191110376490, PMID: 20634421.

22) Belloch A, Morillo C, Luciano JV, García-Soriano G, Cabedo E, Carrió C. Dysfunctional Belief Domains Related To Obsessive-Compulsive Disorder: A Further Examination Of Their Dimensionality And Specificity. Span J Psychol. 2010; 13(1): 376-88. doi: 10.1017/S1138741600003930, PMID: 20480704. 